\title{
Favelas no Brasil e em São Paulo: avanços nas análises a partir da Leitura Territorial do Censo de 2010*
}

\author{
Squatter settlements in Brazil and in São Paulo: improvements \\ in the analyzes from the 2010 Census Territorial Reading
}

Suzana Pasternak Camila D'Ottaviano

\begin{abstract}
Resumo
Pensando nas formas de acesso à moradia da população de baixa renda no Brasil, este artigo pretende analisar, especificamente, as condições de moradia da população favelada, procurando, a partir dos dados censitários disponíveis, identificar o que significa morar numa favela no Brasil na primeira década do século XXI, a partir de algumas questões principais: houve aumento da população favelada no Brasil? Onde esse aumento foi mais expressivo? Como se deu esse aumento: a partir do surgimento de novas favelas ou no aumento das favelas existentes? Quais as características dos domicílios favelados? Houve melhora nos indicadores relacionados à infraestrutura? É também um esforço inédito de análise da base de dados "Leitura Territorial" dos domicílios favelados, base única disponibilizada pelo Censo 2010.
\end{abstract}

Palavras-chave: favelas; assentamentos precários; habitação popular; pobreza urbana; censo demográfico.

\begin{abstract}
In light of the forms of access to housing for lowincome population in Brazil, this paper analyzes, specifically, the living conditions of slum dwellers using available census data. It evaluates the meaning of living in a slum in Brazil during the first decade of the 21st century according to some key issues: was there an increase in the number of slum dwellers in Brazil? Where was this increase most significant? Was this increase produced by new slums or by the increase in slums' population density? What are the characteristics of slum households? Was there any improvement in infrastructure-related indicators? The paper is also an unprecedented effort to analyze the 2010 Census "Territorial Reading", a single database for slum households.
\end{abstract}

Keywords: squatter settlements, shanty towns, popular housing, urban poverty, demographic census 
Pensando nas formas de acesso à moradia da população de baixa renda no Brasil, este artigo pretende analisar, especificamente, as condições de moradia da população favelada, procurando, a partir dos dados censitários disponíveis, identificar o que significa morar numa favela no Brasil na primeira década do século XXI. 0 trabalho insere-se numa linha de estudos que, ao reconhecer o que vem sendo chamado de "heterogeneidade da pobreza urbana", destaca a importância da análise e entendimento das características demográficas e também físico-territoriais dessa pobreza urbana.

Historicamente, 0 acesso à moradia para a população de baixa renda no Brasil se deu, em geral, de forma precária e a partir de três tipos básicos de moradia: os cortiços, as favelas e os loteamentos periféricos, com moradia própria e autoconstrução. Falar de favela é falar das cidades grandes e médias no Brasil no final do século XX e início do século XXI. Embora tenha nascido como uma marca da cidade do Rio de Janeiro, já no início do século XX, nas últimas décadas do século, as favelas se fizeram presentes na maior parte das grandes cidades brasileiras e, desde 2000, também nas cidades médias.

Até meados do século passado, as favelas eram um fenômeno quase que exclusivo da cidade do Rio de Janeiro. Assim, o primeiro levantamento sobre favelas foi realizado apenas em 1948, e somente no Rio de Janeiro, capital federal. Em 1950, o IBGE (Instituto Brasileiro de Geografia e Estatística) decidiu, pela primeira vez, incluir a favela na contagem de população, tendo como estudo de caso específico o Distrito Federal. Em 1953, o próprio IBGE publica o primeiro documento de estudo sobre a realidade das favelas cariocas: o Documento Censitário intitulado "As favelas do Distrito Federal" (IBGE, 1953). Nesse momento, no entanto, os levantamentos quantitativos eram muito desiguais do ponto de vista geográfico. Nas publicações para São Paulo, por exemplo, apenas em 1980 dados específicos sobre favelas apareceram.

Num primeiro momento, a conceituação de favelas era dada por um grupo de moradias que tivessem pelo menos duas das características a seguir:

- proporções mínimas - agrupamentos prediais ou residenciais formados com número geralmente superior a cinquenta;

- tipo de habitação - predominância de casebres ou barracões de aspecto rústico, construídos principalmente com folha de flandres, chapas zincadas ou materiais similares;

- condição jurídica da ocupação - construções sem licenciamento e sem fiscalização, em terrenos de terceiros ou de propriedade desconhecida;

- melhoramentos públicos - ausência, no todo ou em parte, de rede sanitária, luz, telefone e água encanada;

- urbanização - área não urbanizada, com falta de arruamento, numeração ou emplacamento. (Guimarães, 2000, p. 353)

A partir do Censo de 1991, o IBGE passou a adotar o conceito de aglomerado subnormal. ${ }^{1} 0$ conceito, bastante genérico, buscava abarcar a diversidade dos assentamentos irregulares existentes no país. Aglomerado subnormal abarca favelas, invasões, grotas, baixadas, comunidades, vilas, ressacas, mocambos, palafitas, entre outros. Foi nesse Censo Demográfico que os dados relativos às favelas foram levantados de forma homogênea por todo o país. 0 último censo nacional, de 2010, foi o que 
trouxe a maior quantidade de avanços em relação à identificação e levantamento de dados dos aglomerados subnormais, a partir de uma pesquisa morfológica específica, com a identificação georeferenciada e visita de campo preparatória nos aglomerados. Em função da antiga sub-enumeração e do avanço de 2010, a quantificação das favelas pelo Censo 2010 acabou sendo muito mais confiável, gerando um grande crescimento numérico de favelas, em especial na região Norte do país.

De acordo com o Manual de Delimitação dos Setores, o Censo 2010 classifica como aglomerado subnormal "cada conjunto constituído de, no mínimo, 51 unidades habitacionais carentes, em sua maioria, de serviços públicos essenciais, ocupando ou tendo ocupado, até período recente, terreno de propriedade alheia (pública ou particular) e estando dispostas, em geral, de forma desordenada e densa. A identificação atende aos seguintes critérios:

a) Ocupação ilegal da terra, ou seja, construção em terrenos de propriedade alheia (pública ou particular) no momento atual ou em período recente (obtenção do título de propriedade do terreno há dez anos ou menos);

b) Possuírem urbanização fora dos padrões vigentes (refletido por vias de circulação estreitas e de alinhamento irregular, lotes de tamanhos e formas desiguais e construções não regularizadas por órgãos públicos) ou precariedade na oferta de serviços públicos essenciais (abastecimento de água, esgotamento sanitário, coleta de lixo e fornecimento de energia elétrica). (IBGE, 2011)

Além dos avanços relativos às enumeração e características específicas dos domicílios favelados, o Censo Demográfico de 2010 inovou também ao criar uma nova categoria de levantamento chamada de "Leitura Territorial", levantamento bastante completo das características do entorno imediato dos domicílios.

A questão das favelas assume hoje uma dimensão histórica sem precedentes na história do Brasil. Dados do Censo de 2010 mostram que o número de brasileiros vivendo nessas condições passou de 6,5 milhões no ano 2000 para 11,4 milhões em 2010, distribuídos em 6.329 aglomerados subnormais situados em 323 municípios; $88 \%$ desses domicílios estão concentrados em 20 grandes cidades.

Não há ainda, em 2015, dados oficiais que indiquem que o número de favelas tenha aumentado ou diminuído nos últimos anos. Para o município de São Paulo, o último levantamento foi o do Censo de 2010, que contou 1.643 comunidades. Urbanistas e sociólogos concordam em dizer que o número deve ter aumentado. Reportagem do jornal Folha de S.Paulo (2015b), de 25 de agosto de 2015, mostra terrenos desocupados em maio de 2014, totalmente invadidos por unidades de moradia em agosto de 2015, na zona leste do município. Na Mooca, em menos de um mês, um terreno vazio, entre as pistas da Radial Leste, foi ocupado por cerca de 50 famílias. Na avenida Tiquatira, um terreno da CDHU (Companhia de Desenvolvimento Habitacional e Urbano do Estado de São Paulo), vazio em meados de 2014, tem hoje 2.500 casas de alvenaria, com mercadinho, lan house e uma igreja, ocupando uma área de $47 \mathrm{mil} \mathrm{m} \mathrm{m}^{2}$, a poucos metros da marginal do Tietê. Além disso, segue o processo de adensamento das favelas existentes. Em São Paulo, temos também um outro fenômeno recente para o qual ainda existe classificação: a construção de moradias irregulares dentro do 
perímetro de conjuntos habitacionais consolidados, como é o caso do Cingapura Barão de Antonina, junto à marginal Pinheiros, onde 0 terreno entre os edifícios existentes foi dividido entre 23 famílias, das quais sete já construíram suas moradias (Folha de S.Paulo, 2015a, 24 de julho de 2015).

A crise econômica, o preço dos aluguéis, a falta de oferta de moradias para a população de baixa renda são os principais motivos para o crescimento sistemático das favelas, seja com novas ocupações novas, seja a partir da verticalização e adensamentos crescentes.

Por outro lado, a realidade nas favelas brasileiras tem mudado muito nos últimos 20 anos. Além de programas de melhorias urbanísticas e benfeitorias, com grandes obras de saneamento, de reurbanização ou de construção de novas unidades habitacionais, alguns programas de regularização fundiária, sobretudo após a vigência do Estatuto da Cidade, em 2001, têm mudado a forma de acesso à moradia numa favela.

Após uma década com vários programas locais de urbanização de favela, mas, principalmente, após a implementação do PAC - Programa de Aceleração do Crescimento, 2007, e de seu desdobramento, o PAC-Urbanização de Assentamentos Precários, é importante entender qual o impacto efetivo que esses programas tiveram na configuração dos espaços favelados no Brasil, se houve ou não melhoria efetiva na condição de moradia , e consequentemente na condição de vida, da população favelada ao longo da primeira década no século XXI.

A partir dessa preocupação, este trabalho procura responder a algumas questões: houve aumento da população favelada no Brasil? Onde esse aumento foi mais expressivo? Como se deu esse aumento: a partir do surgimento de novas favelas ou no aumento das favelas existentes? Quais as características dos domicílios favelados? Houve melhora nos indicadores relacionados à infraestrutura?

Em 2010, aproximadamente 6\% da população vivia em domicílios localizados em aglomerados subnormais. 0 dado mostra a importância, para programas habitacionais abrangentes, do estudo e entendimento das condições de moradia e das características específicas dos domicílios favelados.

A partir da utilização de dados censitários de 2000 e 2010, pretende-se caracterizar a dinâmica das áreas de favela e da população favelada na década nas diferentes regiões brasileiras. Como estudo de caso específico será analisada a realidade dos espaços favelados da metrópole e do município de São Paulo.

Este artigo representa também um esforço inédito de análise da base de dados relativa à Leitura Territorial dos domicílios favelados, procurando contribuir na análise de uma base de dados primários ainda não explorada e também no entendimento mais abrangente da caracterização dos domicílios favelados brasileiros.

Entende-se que uma análise cuidadosa dessas informações inovadoras pode servir como instrumental para o aprimoramento de políticas e programas de urbanização de favelas no Brasil, uma vez que dados antes apenas disponíveis a partir de levantamentos de campo específicos estão agora disponíveis para todos os aglomerados subnormais recenseados em 2010. Essas análises permitem um esboço do que seria possível - inclusive custos - em projetos de urbanização de favelas. Os dados relativos ao relevo, acesso e adensamento dão 
estimativa, em nível nacional e regional, da quantidade de unidades domiciliares a remover e reconstruir e da possibilidade de urbanização (por exemplo, assentamentos não urbanizáveis, como situados em áreas de declividade acentuada, aterros, solos contaminados, etc.).

E, por último, procurará contribuir para 0 entendimento sobre o que, no Brasil, significa morar em favela atualmente.

\section{Favelas no Brasil, primeiras análises}

As favelas estão presentes em todas as regiões brasileiras. Sua distribuição varia pelo território brasileiro. Em 1991, os aglomerados favelados, segundo o Censo Demográfico, eram 3.187; no ano 2000, atingiram 3.906 assentamentos e, em 2010, o Censo Demográfico contabilizou 6.329 aglomerados.
Assim como os aglomerados, os domicílios e a população favelada também vêm aumentando desde 1980, a taxas maiores que a população total. Entre 1980 e 1991, os domicílios totais para o país cresceram a 3,08\% ao ano, enquanto os favelados cresceram a 8,18\% anuais. No período seguinte - entre 1991 e 2000 - os domicílios totais cresceram a 0,88\% anuais, enquanto os favelados tiveram uma taxa de incremento anual de 4,18\%. Entre 2000 e 2010, a taxa de crescimento anual do parque domiciliar brasileiro foi $0,57 \%$, enquanto a dos domicílios favelados atingiu 6,93\%. A população favelada em 1980 alcançava 2,25 milhões de pessoas; a de 1991, mais de 5 milhões; a do ano 2000, cerca de 7,2 milhões; e, a de 2010, para um total de 3.224.529 domicílios em aglomerados subnormais, era estimada em mais de 14 milhões. Se a população favelada representava $1,62 \%$ da total em 1980 , esse percentual sobe para $2,76 \%$ em 1991 , para $3,04 \%$ no ano 2000 e alcança 5,61\% em 2010.

Tabela 1 - Favelas, por grande região

\begin{tabular}{l|r|r|r}
\hline \multicolumn{1}{c|}{ Região } & 1991 & 2000 & $\mathbf{2 0 1 0}$ \\
\hline Norte & 59 & 185 & 467 \\
Nordeste & 517 & 674 & 1.349 \\
Sudeste & 2.225 & 2.621 & 3.954 \\
Sul & 327 & 392 & 489 \\
Centro-Oeste & 59 & 34 & 106 \\
\hline Brasil & 3.187 & 3.906 & 6.329 \\
\hline
\end{tabular}

Fonte: Censos de 1991, 2000 e 2010. 
Tabela 2 - Domicílios totais e favelados, por grande região

\begin{tabular}{l|c|c|c|c|c|c|c|c}
\hline \multicolumn{1}{c|}{ Região } & 1980 & 1991 & 2000 & 2010 & 1980 & 1991 & \multicolumn{1}{c|}{2000} & 2010 \\
\hline Norte & 1.219 .496 & 2.376 .607 & 3.353 .764 & 3.988 .832 & 12.721 & 97.760 & 178.326 & 463.444 \\
Nordeste & 8.036 .803 & 10.920 .830 & 13.911 .413 & 14.957 .608 & 69.974 & 286.130 & 306.395 & 926.370 \\
Sudeste & 13.761 .346 & 18.839 .621 & 24.699 .909 & 25.227 .877 & 357.330 & 675.846 & 1.038 .608 & 1.607 .375 \\
Sul & 4.826 .030 & 6.598 .962 & 85.092 .284 & 8.904 .120 & 30.077 & 73.325 & 110.411 & 170.054 \\
Centro-Oeste & 1.812 .176 & 2.657 .621 & 3.791 .248 & 4.349 .562 & 10.493 & 11.257 & 16.808 & 57.286 \\
\hline Brasil & 29.657 .831 & 41.395 .632 & 54.267 .618 & 57.427 .999 & 480.595 & 1.141 .324 & 1.650 .548 & 3.224 .520 \\
\hline
\end{tabular}

Fonte: Censos de 1980, 1991, 2000 e 2010.

Tabela 3 - Taxa geométrica de crescimento anual dos domicílios totais e favelados, por grande região, em porcentagem

\begin{tabular}{l|c|c|c|c|c|c}
\hline \multirow{2}{*}{ Região } & \multicolumn{3}{|c|}{ Domicílios totais } & \multicolumn{3}{c}{ Domicílios favelados } \\
\cline { 2 - 7 } & $1980-1991$ & $1991-2000$ & $2000-2010$ & $1980-1991$ & $1991-2000$ & $2000-2010$ \\
\hline Norte & 6,25 & 3,90 & 1,75 & 20,37 & 6,91 & 10,02 \\
Nordeste & 2,83 & 2,73 & 0,73 & 13,66 & 0,76 & 11,70 \\
Sudeste & 2,90 & 3,06 & 0,21 & 5,96 & 4,89 & 4,46 \\
Sul & 2,89 & 2,87 & 0,45 & 8,44 & 4,65 & 4,41 \\
Centro-Oeste & 3,54 & 4,03 & 1,38 & 0,64 & 4,55 & 3,05 \\
\hline Brasil & 3,08 & 3,05 & 0,57 & 8,18 & 4,18 & 6,93 \\
\hline
\end{tabular}

Fonte: Censos de 1980, 1991, 2000 e 2010 (IBGE).

Tabela 4 - Alguns aspectos da infraestrutura domiciliar dos domicílios favelados, por grande região, 2010

\begin{tabular}{|c|c|c|c|c|c|c|c|c|c|c|c|c|}
\hline \multirow{4}{*}{$\begin{array}{l}\text { Grandes } \\
\text { Regiôes }\end{array}$} & \multicolumn{12}{|c|}{ Algumas caracteristicas dos domicilios } \\
\hline & \multicolumn{2}{|c|}{$\begin{array}{l}\text { Forma de abastecimento } \\
\text { de água - } \%\end{array}$} & \multicolumn{4}{|c|}{ Tipo de esgotamento sanitário - \% } & \multicolumn{3}{|c|}{ Destino do lixo - \% } & \multicolumn{3}{|c|}{ Existência de energia elétrica - \% } \\
\hline & \multirow[b]{2}{*}{$\begin{array}{c}\text { Rede geral } \\
\text { de } \\
\text { distribuição }\end{array}$} & \multirow[b]{2}{*}{ Outra } & \multirow[b]{2}{*}{$\begin{array}{l}\text { Rede geral } \\
\text { de esgoto } \\
\text { ou pluvial }\end{array}$} & \multirow[b]{2}{*}{$\begin{array}{l}\text { Fossa } \\
\text { séptica }\end{array}$} & \multirow[b]{2}{*}{ Outra } & \multirow[b]{2}{*}{$\begin{array}{c}\text { Não tinham } \\
\text { banheiro } \\
\text { ou } \\
\text { sanitário }\end{array}$} & \multicolumn{2}{|c|}{ Coletado } & \multirow[b]{2}{*}{ Outra } & \multirow{2}{*}{$\begin{array}{l}\text { De companhia } \\
\text { distribuidora } \\
\text { e com } \\
\text { medidor de } \\
\text { uso exclusivo } \\
\text { do domicilio }\end{array}$} & \multirow[b]{2}{*}{ Outra } & \multirow[b]{2}{*}{$\begin{array}{c}\text { Não existe } \\
\text { energia } \\
\text { elétrica }\end{array}$} \\
\hline & & & & & & & $\begin{array}{c}\text { Diretamente } \\
\text { por serviço } \\
\text { de limpeza }\end{array}$ & $\begin{array}{c}\text { Em } \\
\text { caçamba } \\
\text { de serviço } \\
\text { de limpeza }\end{array}$ & & & & \\
\hline Norte & 59,91 & 40,09 & 18,42 & 26,96 & 52,20 & 2,41 & 84,85 & 8,79 & 6,36 & 68,09 & 31,34 & 0,57 \\
\hline Nordeste & 89,81 & 10,19 & 49,07 & 13,57 & 35,64 & 1,73 & 72,63 & 19,87 & 7,50 & 82,99 & 16,60 & 0,41 \\
\hline Sudeste & 94,59 & 5,41 & 72,00 & 4,15 & 23,63 & 0,22 & 74,21 & 23,21 & 2,58 & 69,21 & 30,63 & 0,15 \\
\hline Sul & 96,62 & 3,38 & 63,36 & 13,14 & 22,37 & 1,13 & 92,80 & 5,88 & 1,31 & 63,24 & 36,43 & 0,33 \\
\hline Centro-Oeste & 94,46 & 5,54 & 19,79 & 23,00 & 56,91 & 0,30 & 67,02 & 22,44 & 10,54 & 58,58 & 41,17 & 0,24 \\
\hline Brasil & 88,34 & 11,66 & 56,33 & 10,94 & 31,71 & 1,02 & 76,14 & 19,25 & 4,61 & 72,51 & 27,20 & 0,30 \\
\hline
\end{tabular}

Fonte: Censo de 2010. 
A Tabela 4 mostra os principais resultados dos aspectos de infraestrutura nos domicílios favelados, por região brasileira, em 2010. A situação dos domicílios favelados no Brasil como um todo em relação ao abastecimento de água não é alarmante, já que apenas $12 \%$ deles não são abastecidos por rede publica. $\mathrm{Na}$ região Norte, entretanto, esse indicador é preocupante, já que $40 \%$ das unidades domiciliares não estão ligadas à rede pública de abastecimento de água, e $38 \%$ se servem de poços e/ ou nascentes. Para o Brasil como um todo a proporção de domicílios em aglomerados subnormais que utilizam poços ou nascentes alcança quase $10 \%$ das unidades habitacionais. Na região Nordeste, a situação ainda se revela crítica, com quase $8 \%$ das casas utilizando poço ou nascente.

Em relação ao destino dos dejetos, a situação mostra-se ainda mais preocupante: apenas $56 \%$ dos domicílios nas favelas brasileiras estavam ligados à rede de esgotamento sanitário em 2010. Ou seja, 352 mil unidades declararam-se conectadas a fossas sépticas, o que em geral costuma dar problemas de manutenção e, consequentemente, de contaminação do lençol freático, 513 mil utilizam fossa rudimentar, 200 mil jogam seus dejetos diretamente às valas, rios, lagos. Os valores são particularmente altos no Norte e no Nordeste, onde apenas $18,42 \%$ e $49,07 \%$ respectivamente apresentavam ligação à rede pública de esgoto. Na região Sul só $63 \%$ dos domicílios tinha ligação à rede pública, enquanto $20 \%$ tinham fossa e $15 \%$ jogavam seus efluentes em valas, rios, lagos ou mar. Mesmo no Sudeste, onde a situação sanitária apresenta indicadores melhores, 4,24\% das casas têm fossa rudimentar, 6,65\% jogam seus dejetos em valas e $11 \%$ o fazem em rios, lagos ou direto no mar.

Um indicador que apresenta melhora significativa, mostrando resultados dos esforços municipais, é o relativo à coleta de lixo. Para o Brasil como um todo, existe coleta domiciliar em 76,4\% dos domicílios, oscilando entre $67 \%$ no Centro Oeste e $85 \%$ no Norte. Para quem conhece e visita as favelas com frequência, esse dado espanta: o que mais chama a atenção nesses assentamentos, em geral, é a existência de lixo nas ruas e espaços livres. Vale a pena lembrar que a afirmação censitária de que existe coleta domiciliar não indica sua frequência. Além disso, em 20,18\% dos domicílios a coleta dá-se por caçambas, ou seja, o lixo deve ser levado até um recipiente para que a coleta possa acontecer. Coleta em caçamba, aliada a uma frequência irregular de coleta e a altas densidades demográficas resultam sempre em acúmulo de detritos sólidos, possibilitando a presença de baratas, roedores e outros vetores indesejáveis. Mesmo no Sudeste, a coleta de lixo em caçambas atinge $24 \%$ dos domicílios.

No Brasil como um todo, a densidade demográfica nos assentamentos subnormais atingiu 67,5 hab/ha, e no Sudeste essa média é de 99 hab/ha. A média mistura locais com assentamentos densíssimos, onde a densidade média municipal atinge 326 hab/ha como em Itapevi, na Região Metropolitana de São Paulo (RMSP), 286 hab/ha em Osasco (RMSP) e 297 hab/ha em São Paulo. Esses valores médios elevados indicam favelas com densidades altíssimas, onde a coleta de lixo, para ser eficaz, deveria ser diária ou mesmo mais de uma vez ao dia.

0 aspecto infraestrutural com maior sucesso nas favelas brasileiras refere-se à energia 
elétrica: $96,16 \%$ dos domicílios favelados a recebem, $72,51 \%$ deles com medidor de uso exclusivo. As favelas do Nordeste são as que apresentam maior proporção de medidores exclusivos, com $83 \%$ das suas unidades de moradia os utilizando. No Sudeste, o uso de medidor exclusivo restringia-se a $69 \%$ dos domicílios, no Sul a $63 \%$ e no Centro Oeste a $58 \%$.

0 Censo de 2010 permitiu, pela primeira vez, uma melhor leitura territorial dos assentamentos subnormais, através de verificação da topografia do local, declividade, densidade demográfica, ocupação, existência de espaçamento entre domicílios, de arruamento, acessibilidade e número de pavimentos de cada unidade de moradia.

Verifica-se que, para o Brasil como um todo, $21 \%$ das favelas têm seus domicílios em local de declividade acentuada. No Nordeste e o Sudeste, esses domicílios em aclive/declive forte são $1 / 4$ do total. Em princípio, podem ser unidades sujeitas a deslizamento. Nas regiões Norte e Centro-Oeste, o percentual de moradias em declives acentuados é baixo, dominando as unidades em terrenos planos e/ou declives moderados. Mas um total de 668 mil moradias em terrenos de forte declividade fornece um indicador importante para projetos de urbanização: são 230 mil no Nordeste e 398 mil no Sudeste que poderão necessitar de remoção ou trabalhos de contenção de encostas.

Enfatizando outros aspectos do relevo, a Tabela 5 fornece informações importantes sobre a localização dos domicílios: 19,20\% dos domicílios favelados brasileiros situam-se em encosta; $17,63 \%$ em colinas suaves; e $40,20 \%$ em terrenos planos. Tal como informa a Tabela 6 , é no Nordeste e no Sudeste que a localização em encostas aparece mais fortemente. Embora a proporção seja pequena, de apenas 0,35\%, o número absoluto de domicílios em terrenos contaminados não é desprezível: são mais de 11 mil para o Brasil, sendo mais de 4 mil só no Sudeste. Em faixas de domínio de rodovias, ferrovias, gasodutos e oleodutos, e transmissão de energia, localizam-se 113.921 unidades domiciliares, que terão seguramente que enfrentar algum tipo de remoção. Cerca

Tabela 5 - Relevo: declividade dos domicílios em aglomerados subnormais, por grande região, 2010

\begin{tabular}{l|c|c|c}
\hline \multirow{2}{*}{ Grandes Regiões } & \multicolumn{2}{|c}{ Domicílios em aglomerados subnormais com declividades } \\
\cline { 2 - 4 } & Plano & Aclive/declive moderado & Aclive/declive acentuado \\
\hline Norte & 83,12 & 14,69 & 2,19 \\
Nordeste & 51,76 & 23,48 & 24,76 \\
Sudeste & 44,00 & 31,26 & 24,74 \\
Sul & 54,51 & 28,09 & 17,40 \\
Centro-Oeste & 48,59 & 47,50 & 3,91 \\
\hline Brasil & 52,49 & 26,76 & 20,75 \\
\hline
\end{tabular}

Fonte: Censo Demográfico de 2010. Leitura territorial. 
Tabela 6 - Localização dos domicílios em aglomerados subnormais, por grande região, 2010

\begin{tabular}{|c|c|c|c|c|c|c|c|c|c|c|c|c|c|c|}
\hline \multirow[b]{2}{*}{$\begin{array}{l}\text { Grandes } \\
\text { Regiões }\end{array}$} & \multicolumn{14}{|c|}{ Domicílios em aglomerados sub normais - \% } \\
\hline & 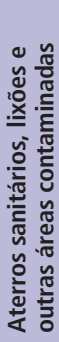 & 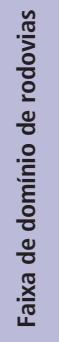 & 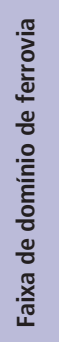 & 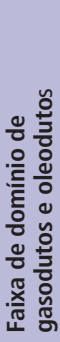 & 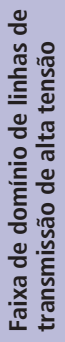 & 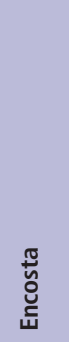 & 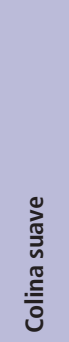 & $\frac{\circ}{\frac{\pi}{a}}$ & 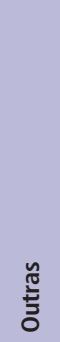 & 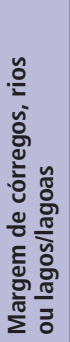 & 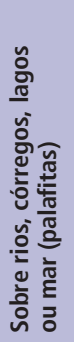 & $\begin{array}{l}\frac{n}{0} \\
\frac{5}{5} \\
\frac{0}{0} \\
\frac{\pi}{\frac{\pi}{2}} \\
\frac{2}{2}\end{array}$ & 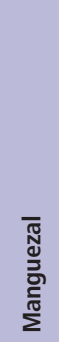 & 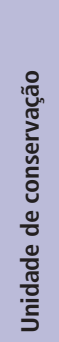 \\
\hline Norte & - & 0,57 & 0,05 & - & 0,24 & 0,53 & 2,63 & 76,15 & 4,29 & 10,72 & 4,82 & - & - & - \\
\hline Nordeste & 0,36 & 1,47 & 1,10 & 0,07 & 0,88 & 23,91 & 18,42 & 38,77 & 2,35 & 8,81 & 0,14 & 2,34 & 1,10 & 0,28 \\
\hline Sudeste & 0,26 & 1,68 & 1,45 & 0,22 & 1,04 & 22,30 & 22,02 & 30,53 & 2,97 & 14,54 & 0,90 & 0,24 & 0,59 & 1,24 \\
\hline Sul & 1,97 & 1,42 & 1,40 & - & 0,76 & 20,03 & 16,25 & 35,38 & 7,29 & 13,54 & - & 0,28 & 1,40 & 0,29 \\
\hline Centro-Oeste & 0,43 & 0,85 & - & - & 0,30 & 4,19 & 7,38 & 58,27 & 0,74 & 26,61 & - & - & - & 1,22 \\
\hline Brasil & 0,35 & 1,43 & 1,12 & 0,13 & 0,85 & 19,20 & 17,63 & 40,20 & 3,17 & 12,51 & 1,18 & 0,81 & 0,69 & 0,74 \\
\hline
\end{tabular}

Fonte: Censo de 2010. Leitura territorial.

de 27,5 mil estão sob linhas de alta tensão, correndo forte perigo. No Sudeste, mais de $1 \%$ dos domicílios encontram-se nessa situação, assim como 1,45\% em faixas de domínio de ferrovias e 1,68\% em faixas de domínio de rodovias. São espaços onde não deveria haver qualquer tipo de uso, especialmente residencial, e que são aproveitados para ocupações. Mais de 400 mil domicílios favelados localizam-se em margens de rios ou lagos, e 38 mil são palafitas (1,18\% do total). Como seria esperado, as palafitas abundam no Norte (59\% do total de domicílios em palafitas estão na região Norte). No Sudeste, quase 20 mil casas localizam-se em unidades de conservação.
A densidade média dos assentamentos subnormais é relativamente alta, quando comparada às densidades demográficas médias dos municípios como um todo: 67,5 hab/ ha. Esses assentamentos ocupam uma área de 169.170,3 hectares, superfície maior que a do município de São Paulo, com 150.900 hectares e densidade média de quase 75 hab/ha em 2010. A densidade média das favelas no Sudeste ultrapassa a média paulistana. Lembrando que $64,57 \%$ dos domicílios favelados no Brasil têm um só pavimento, esse indicador aponta a pouca área livre existente nesses assentamentos e a decorrente dificuldade de implementação de projetos de urbanização. 
Tabela 7 - Domicílios, população, área e densidades nos aglomerados subnormais, por grande região, 2010

\begin{tabular}{|c|c|c|c|c|c|c|}
\hline \multirow[b]{2}{*}{$\begin{array}{l}\text { Grandes } \\
\text { Regiões }\end{array}$} & \multicolumn{6}{|c|}{ Setores censitários em aglomerados subnormais } \\
\hline & Total & $\begin{array}{l}\text { Número de } \\
\text { domicílios } \\
\text { particulares } \\
\text { ocupados }\end{array}$ & $\begin{array}{l}\text { População } \\
\text { residente em } \\
\text { domicílios } \\
\text { particulares }\end{array}$ & $\begin{array}{l}\text { Área } \\
\text { (ha) }\end{array}$ & $\begin{array}{c}\text { Densidade } \\
\text { demográfica } \\
\text { (hab/ha) }\end{array}$ & $\begin{array}{c}\text { Densidade } \\
\text { de domicílios } \\
\text { particulares } \\
\text { ocupados } \\
\text { (dom/ha) }\end{array}$ \\
\hline Norte & 1.915 & 463.444 & 1.849 .604 & $46.513,8$ & 39,8 & 10,0 \\
\hline Nordeste & 4.005 & 926.370 & 3.198 .061 & $45.198,8$ & 70,8 & 20,5 \\
\hline Sudeste & 8.804 & 1.607 .375 & 5.580 .869 & $56.290,3$ & 99,1 & 28,6 \\
\hline Sul & 871 & 170.054 & 590.500 & $15.038,2$ & 39,3 & 11,3 \\
\hline Centro-Oeste & 273 & 57.286 & 206.610 & $6.129,2$ & 33,7 & 9,3 \\
\hline Brasil & 15.868 & 3.224 .529 & 11.425 .644 & $169.170,3$ & 67,5 & 19,1 \\
\hline
\end{tabular}

Fonte: Censo de 2010. Leitura territorial.

Tabela 8 - Pavimentos dos domicílios em aglomerados subnormais, por grande região, 2010

\begin{tabular}{l|c|c|c}
\hline \multirow{2}{*}{ Grandes Regiões } & \multicolumn{3}{|c}{ Domicílios por pavimentos $-\%$} \\
\cline { 2 - 4 } & Um pavimento & Dois pavimentos & Três pavimentos ou mais \\
\hline Norte & 97,04 & 2,77 & 0,19 \\
Nordeste & 70,87 & 25,08 & 4,04 \\
Sudeste & 47,38 & 44,52 & 8,10 \\
Sul & 92,29 & 7,71 & - \\
Centro-Oeste & 100,00 & - & - \\
\hline Brasil & 64,57 & 30,21 & 5,23 \\
\hline
\end{tabular}

Fonte: Censo de 2010. Leitura Territorial.

Tabela 9 - Ocupação do setor censitário pelos domicílios favelados

\begin{tabular}{l|c|c|c|c|c}
\hline \multirow{2}{*}{$\begin{array}{l}\text { Grandes } \\
\text { Regiões }\end{array}$} & \multicolumn{5}{|c}{ Domicílios ocupados em setores censitários de aglomerados subnormais - \% } \\
\cline { 2 - 6 } & $\begin{array}{c}\text { Em todo setor } \\
\text { (95\% ou mais) }\end{array}$ & $\begin{array}{c}\text { Na maior parte } \\
\text { do setor } \\
\text { (entre 60 e 94,99\%) }\end{array}$ & $\begin{array}{c}\text { Em metade do } \\
\text { setor } \\
\text { (entre 40 e 59,99\%) }\end{array}$ & $\begin{array}{c}\text { Na menor parte } \\
\text { do setor } \\
\text { (entre 5 e 39,99\%) }\end{array}$ & $\begin{array}{c}\text { Em nenhuma } \\
\text { parte do setor } \\
\text { (menos de 5\%) }\end{array}$ \\
\hline Norte & 18,25 & 58,11 & 10,46 & 11,17 & 2,01 \\
Nordeste & 9,93 & 20,24 & 20,44 & 41,71 & 32,56 \\
Sudeste & 6,49 & 21,30 & 16,53 & 29,86 & 23,12 \\
Sul & 9,92 & 25,73 & 21,91 & 9,95 & 12,58 \\
Centro-0este & 13,02 & 62,28 & 11,38 & 31,57 & 3,37 \\
\hline Brasil & 9,46 & 27,25 & 16,98 & 14,74 \\
\hline
\end{tabular}

Fonte: Censo de 2010. Leitura territorial. 
Embora a maioria das unidades residenciais faveladas ainda seja horizontal, a proporção de casas com dois pavimentos é alta: $30,21 \%$ das unidades brasileiras. Na região Sudeste, essa porcentagem chega a 44,52\%, e $8,10 \%$ têm 3 e mais pavimentos. No Nordeste também, a proporção de domicílios com mais de um pavimento alcançou $29,12 \%$. Já em locais com mais área disponível, como no Centro-Oeste e no Norte, a quase totalidade é de unidades com apenas um pavimento.

Observando a ocupação do solo do setor censitário pelo parque domiciliar, para o país como um todo ainda há espaço vago nos setores censitários dos aglomerados favelados: em $32 \%$, a ocupação do solo do setor censitário situa-se entre 5\% e 40\%. 0 índice de ocupação é menor no Centro Oeste, atingindo valor mais alto nas favelas do Nordeste, onde $20 \%$ dos setores mostravam ocupação entre $60 \%$ e 95\%, 20\% acusavam índice de ocupação de metade do setor e $41 \%$ dos domicílios ocupavam setores com $5 \%$ a $40 \%$ de ocupação. As favelas da região Norte também utilizam intensamente o espaço disponível, com 18\% dos domicílios em setores totalmente ocupados e $58 \%$ das unidades em setores muito ocupados (entre $60 \%$ e $95 \%$ de ocupação). $\mathrm{E}$, embora a região Sudeste apresente a maior densidade demográfica, é a que mostra a maior proporção de domicílios em setores pouco ocupados (com 5\% de índice de ocupação). Assim, no Sudeste, há mais "espaço de respiro", que permitiria realocação de moradias, se preciso, assim como no Sul. No Nordeste, isso também parece possível, mas a ocupação tem menos superfície livre disponível.

A Tabela 10 complementa as indicações acima, evidenciando os espaçamentos entre os domicílios já existentes, sem contar setores mais vazios do assentamento. Para o Brasil como um todo, em $73 \%$ dos domicílios favelados não há espaçamento nenhum, ou seja, a única possibilidade de expansão seria a vertical. Só existe espaçamento grande em menos de 25 mil casas, $0,76 \%$ do total de unidades faveladas. No Nordeste, a proporção de unidades de moradia sem nenhum espaçamento

Tabela 10 - Existência de espaçamento entre unidades habitacionais, aglomerados subnormais, grandes regiões, 2010

\begin{tabular}{l|c|c|c|c}
\hline \multirow{2}{*}{ Grandes Regiões } & \multicolumn{3}{|c}{ Domicílios ocupados em setores censitários de aglomerados sub normais } \\
\cline { 2 - 5 } & Sem espaçamento & Espaçamento médio & Espaçamento grande & Total \\
\hline Norte & 298.247 & 158.721 & 6.476 & 463.444 \\
Nordeste & 761.193 & 157.905 & 7.272 & 926.370 \\
Sudeste & 1.219 .434 & 379.442 & 8.499 & 1.607 .375 \\
Sul & 58.778 & 109.371 & 1.905 & 170.054 \\
Centro-Oeste & 4.906 & 52.035 & 345 & 57.286 \\
\hline Brasil & 2.342 .558 & 857.474 & 24.497 & 3.224 .529 \\
\hline
\end{tabular}

Fonte: Censo de 2010. Leitura territorial. 
atingiu o máximo, com mais de $82 \%$ das unidades habitacionais sem espaço algum entre elas. No Sudeste, em $23 \%$ dos domicílios há espaçamento médio, o que significa que dá para abrir passagens e também garantir iluminação e ventilação.

As três últimas tabelas da Leitura Territorial procuram mostrar a existência de arruamento e a acessibilidade possível nas favelas brasileiras. A Tabela 11 mostra que apenas $21 \%$ dos domicílios em aglomerados subnormais situam-se em setores censitários com arruamento completo; $28,9 \%$ localizam-se em setores com arruamento na maior parte do setor (entre 60 a $95 \%$ do setor). Quase 7,5\% ficam em setores sem nenhum arruamento. A situação mais premente em termos de arruamento é no Sudeste, onde apenas $14 \%$ dos domicílios estão em setores completamente arruados. E $11 \%$ em setores sem rua nenhuma. Percebe-se que na região Sudeste existe mais de 600 mil domicílios sem acesso, o que vai se refletir na informação seguinte, nas Tabelas 12 e 13, onde se vê que no Sudeste só $40 \%$ dos domicílios são servidos por rua, enquanto em $53 \%$ deles o acesso se dá por beco ou travessa. Isso se reflete nas 611.873 unidades no Sudeste só acessíveis a pé ou por bicicleta e nas 24 mil que não são acessíveis por caminho ou trilha nenhuma. No Nordeste, a presença de escadarias é marcante, com $9 \%$ dos domicílios acessíveis por escada, e, portanto, apenas a pé.

Tabela 11 - Existência de arruamento nos setores censitários subnormais, regiões brasileiras, 2010

\begin{tabular}{l|c|c|c|c|c}
\hline \multirow{2}{*}{$\begin{array}{l}\text { Grandes } \\
\text { Regiões }\end{array}$} & \multicolumn{3}{|c|}{ Domicílios particulares em setores censitários de aglomerados subnormais com arruamento - \% } \\
\cline { 2 - 6 } & $\begin{array}{c}\text { Em todo setor } \\
\text { (95\% ou mais) }\end{array}$ & $\begin{array}{c}\text { Na maior parte } \\
\text { do setor } \\
\text { (entre 60 e 94,99\%) }\end{array}$ & $\begin{array}{c}\text { Em metade } \\
\text { do setor } \\
\text { (entre 40 e 59,99\%) }\end{array}$ & $\begin{array}{c}\text { Na menor parte do } \\
\text { setor } \\
\text { (entre 5 e 39,99\%) }\end{array}$ & $\begin{array}{c}\text { Em nenhuma } \\
\text { parte do setor } \\
\text { (menos de 5\%) }\end{array}$ \\
\hline Norte & 51,72 & 32,50 & 6,51 & 6,73 & 2,53 \\
Nordeste & 15,25 & 23,45 & 22,74 & 33,45 & 27,47 \\
Sudeste & 14,04 & 28,00 & 19,77 & 17,44 & 10,73 \\
Sul & 25,38 & 34,95 & 16,96 & 2,51 & 5,27 \\
Centro-0este & 36,97 & 55,35 & 3,80 & 25,23 & 1,37 \\
\hline Brasil & 20,81 & 28,19 & 18,29 & 7,48 \\
\hline
\end{tabular}

Fonte: Censo de 2010. Leitura territorial. 
Tabela 12 - Domicílios em aglomerados subnormais por tipo de via de circulação, regiões brasileiras, 2010

\begin{tabular}{l|c|c|c|c|c|c|c}
\hline \multirow{2}{*}{$\begin{array}{l}\text { Grandes } \\
\text { Regiões }\end{array}$} & Rua & $\begin{array}{c}\text { Beco/ } \\
\text { Travessa }\end{array}$ & Escadaria & Rampa & $\begin{array}{c}\text { Passarela/ } \\
\text { pinguela }\end{array}$ & $\begin{array}{c}\text { Caminho/ } \\
\text { trilha }\end{array}$ & $\begin{array}{c}\text { Não existe via } \\
\text { de circulação } \\
\text { interna }\end{array}$ \\
\cline { 2 - 8 } & 81,44 & 11,70 & - & 0,06 & 5,46 & 1,16 & 0,17 \\
Norte & 50,10 & 36,20 & 8,78 & 1,07 & 0,14 & 3,32 & 0,37 \\
Sudeste & 40,09 & 53,09 & 3,43 & 0,12 & 0,25 & 1,52 & 1,49 \\
Sul & 76,04 & 21,03 & 0,13 & 0,17 & 0,12 & 2,12 & 0,39 \\
Centro-Oeste & 96,49 & 1,96 & - & - & - & 1,55 & - \\
\hline Brasil & 51,81 & 39,69 & 4,24 & 0,39 & 0,96 & 2,02 & 0,89 \\
\hline
\end{tabular}

Fonte: Censo Demográfico de 2010. Leitura territorial.

Tabela 13 - Acessibilidade possível para domicílios em aglomerados subnormais, grandes regiões, 2010

\begin{tabular}{|c|c|c|c|c|c|}
\hline \multirow{2}{*}{$\begin{array}{l}\text { Grandes } \\
\text { Regiões }\end{array}$} & \multicolumn{5}{|c|}{ Domicílios em aglomerados sub normais - \% } \\
\hline & Caminhão & Carro & Motocicleta & A pé / bicicleta & $\begin{array}{l}\text { Não existem } \\
\text { vias internas }\end{array}$ \\
\hline Norte & 34,19 & 46,58 & 11,38 & 7,68 & 0,17 \\
\hline Nordeste & 19,79 & 30,28 & 19,12 & 30,44 & 0,37 \\
\hline Sudeste & 17,96 & 22,16 & 20,33 & 38,07 & 1,49 \\
\hline Sul & 30,46 & 49,04 & 9,90 & 10,20 & 0,39 \\
\hline Centro-Oeste & 18,48 & 76,18 & 3,04 & 2,31 & - \\
\hline Brasil & 21,49 & 30,38 & 17,84 & 29,40 & 0,89 \\
\hline
\end{tabular}

Fonte: Censo 2010. Leitura territorial. 


\section{A Região Metropolitana de São Paulo}

A Região Metropolitana de São Paulo apresenta a maior concentração de favelas do Brasil, com 1.703 aglomerados (27\% do total de favelas brasileiras) e população favelada de mais de 2 milhões de pessoas (19\% da população favelada brasileira). Apenas as cidades de São Paulo, Guarulhos, Osasco e Diadema tinham, no ano 2000, 938 favelas - cerca de $1 / 4$ das favelas do país. Em 2010, esses quatro municípios contavam com 1.348 aglomerados, $21 \%$ do total de aglomerados no Brasil. Conforme mostra a Tabela 14, a proporção de domicílios favelados nos municípios periféricos vem aumentando desde 1991. Assim, essa proporção era de 5,71\% em 1991, alcança 8,4\% em 2000 e chega a 9,79\% em 2010. A taxa de crescimento das casas faveladas nos municípios periféricos foi bem maior que a dos domicílios favelados na capital entre 1991 e 2000 (quase o dobro). Já na década seguinte, entre 2000 e 2010, a situação se inverte, mostrando que, apesar do crescimento da proporção de casas faveladas na periferia, a taxa de crescimento na capital foi enorme: $24 \%$ do crescimento absoluto das casas no Município de São Paulo foi devido ao crescimento das unidades em favela. Nos municípios periféricos, o crescimento de domicílios é integrado pelo crescimento de 52.503 unidades faveladas, o que representa $11 \%$ do crescimento do parque domiciliar dando-se em assentamentos favelados. Embora a favelização esteja atingindo os municípios da periferia metropolitana, na última década a concentração relativa aumentou na capital. Entre os 39 municípios metropolitanos, incluindo São Paulo, 24 apresentam favelas no seu tecido urbano. Em alguns municípios da metrópole, o percentual de domicílios favelados é grande, superior a 10\%: Taboão da Serra $(11,02 \%)$, São Paulo (11,42\%), Osasco (12,06\%), Santo André (12,67\%), Embu (13,14\%), Guarulhos $(15,98 \%)$, São Bernardo $(20,04 \%)$, Mauá $(20,24 \%)$ e Diadema $(20,97 \%)$.

Tabela 14 - Região Metropolitana de São Paulo. Taxas geométricas de crescimento domiciliar totais e favelados, 1991 a 2010, em porcentagem e proporção de domicílios favelados

\begin{tabular}{l|c|c|c|c|c|c|c}
\hline \multirow{2}{*}{ Unidade Geográfica } & \multicolumn{3}{|c|}{ Proporção de favelados - \% } & \multicolumn{2}{c|}{ Taxas com totais - \% } & \multicolumn{2}{c}{ Taxas com favelados - \% } \\
\cline { 2 - 8 } & 1991 & 2000 & 2010 & $1991-2000$ & $\mathbf{2 0 0 0 - 2 0 1 0}$ & $1991-2000$ & $2000-2010$ \\
\hline Município de São Paulo & 5,58 & 7,41 & 9,95 & 1,62 & 1,64 & 4,86 & 4,68 \\
Outros municípios & 5,95 & 9,23 & 9,58 & 2,88 & 2,11 & 8,02 & 2,49 \\
Região Metropolitana & 5,72 & 8,14 & 9,79 & 2,11 & 1,83 & 6,18 & 3,74 \\
\hline
\end{tabular}

Fonte: Censos Demográficos de 1991, 200 e 2010. 
Tabela 15 - RMSP - Densidade demográfica e de domicílios 2010

\begin{tabular}{l|c|c|c|c|c|c}
\hline \multirow{2}{*}{ RMSP } & \multicolumn{6}{|c|}{ Setores censitários em aglomerados sub normais } \\
\cline { 2 - 7 } & Total & $\begin{array}{c}\mathbf{N}^{\circ} \text { de } \\
\text { domicílios } \\
\text { particulares } \\
\text { ocupados }\end{array}$ & $\begin{array}{c}\text { População } \\
\text { residente em } \\
\text { domicílios } \\
\text { particulares }\end{array}$ & Área (ha) & $\begin{array}{c}\text { Densidade } \\
\text { demográfica } \\
\text { (hab/ha) }\end{array}$ & $\begin{array}{c}\text { Densidade de } \\
\text { domicílios } \\
\text { particulares } \\
\text { ocupados (dom/ha) }\end{array}$ \\
\hline RMSP & 3.246 & 596.479 & 2.162 .368 & $8.834,8$ & 244,8 & 67,5 \\
MSP & 1.998 & 355.756 & 1.280 .400 & $4.304,6$ & 297,4 & 82,6 \\
outros & 1.248 & 240.723 & 881.968 & 4.530 & 195,0 & 53,1 \\
\hline
\end{tabular}

Fonte: Censo 2010. Leitura territorial.

Tabela 16 - RMSP: domicílios em aglomerados subnormais, por número de pavimentos, 2010

\begin{tabular}{l|c|c|c}
\hline \multirow{2}{*}{ RMSP } & \multicolumn{2}{|c}{ Domicílios em aglomerados subnormais } \\
\cline { 2 - 4 } & Um pavimento & Dois pavimentos & Três pavimentos ou mais \\
\hline RMSP & 37,71 & 57,97 & 4,32 \\
MSP & 30,48 & 65,28 & 4,24 \\
outros & 48,40 & 47,17 & 4,44 \\
\hline
\end{tabular}

Fonte: Censo Demográfico de 2010, leitura territorial.

A densidade demográfica média nas favelas da metrópole apresenta-se bastante alta, com 244,8 hab/ha. Para a região Sudeste como um todo, ela foi de 99,1 hab/ha em 2010. Alguns municípios da metrópole têm densidades especialmente altas, como Diadema $(458,9$ hab/ha), Cotia (355,8 hab/ha), Caieiras (340.5 hab/ha), Itapevi (326,8 hab/ha). 0 município de São Paulo também tem densidade demográfica elevada nas favelas, com 297,4 hab/ha. A densidade para o município como um todo não alcança 80 habitantes por hectare.

As altas densidades domiciliares são reflexo, em geral, da verticalização das unidades, embora, é claro, podem-se verificar altas densidades demográficas sem verticalização, sobretudo em assentamentos favelados, onde o espaçamento entre unidades, quanto existe, é pequeno. Mas chama a atenção que a proporção de unidades com dois e mais pavimentos na metrópole seja superior às construções horizontais: $62,3 \%$ têm dois e mais pavimentos, enquanto $37,7 \%$ são horizontais. No município central, isso é ainda mais evidente: $69,5 \%$ das casas têm mais de um pavimento. Nos outros municípios metropolitanos, essa porcentagem alcança 51,6\% dos domicílios. A mudança dos materiais de construção, com a introdução de lajes de concreto e alvenaria de bloco, aliada à falta de espaços vagos mesmo nas favelas, resultou num tecido verticalizado, distinto das favelas dos anos 1960, horizontais e de madeira. 
Tabela 17 - RMSP: presença de espaçamento entre domicílios favelados, 2010

\begin{tabular}{l|c|c|c}
\hline \multirow{2}{*}{ RMSP } & \multicolumn{2}{|c}{ Domicílios em setores censitários de aglomerados subnormais - \% } \\
\cline { 2 - 4 } & Sem espaçamento & Espaçamento médio & Espaçamento grande \\
\hline RMSP & 85,21 & 14,61 & 0,18 \\
MSP & 84,26 & 15,56 & 0,19 \\
Outros municípios & 86,63 & 13,20 & 0,17 \\
\hline
\end{tabular}

Fonte: Censo Demográfico de 2010, leitura territorial.

Tabela 18 - RMSP: localização dos domicílios nos aglomerados subnormais, 2010

\begin{tabular}{|c|c|c|c|c|c|c|c|c|c|c|c|c|}
\hline \multirow[b]{2}{*}{ RMSP } & \multicolumn{12}{|c|}{ Domicilios em aglomerados subnormais - $\%$} \\
\hline & 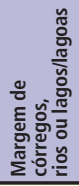 & 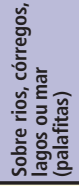 & 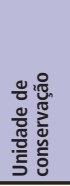 & 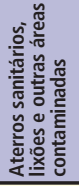 & 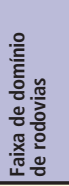 & 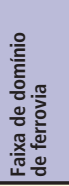 & 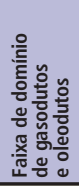 & 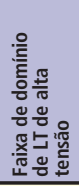 & 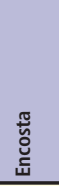 & 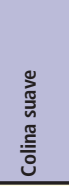 & 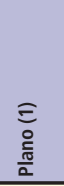 & 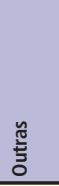 \\
\hline RMSP & 24,91 & 1,53 & 1,71 & 0,33 & 0,85 & 0,76 & 0,38 & 1,81 & 20,26 & 24,78 & 19,60 & 3,06 \\
\hline MSP & 24,69 & 1,75 & 2,43 & 0,33 & 0,74 & 0,94 & 0,09 & 1,22 & 19,06 & 22,05 & 23,18 & 3,50 \\
\hline Outros & 25,24 & 1,21 & 0,65 & 0,34 & 1,01 & 0,49 & 0,81 & 2,69 & 22,04 & 28,80 & 14,31 & 2,40 \\
\hline
\end{tabular}

Fonte: Censo de 2010, leitura territorial.

Tabela 19 - RMSP: existência e tipo de acesso, aglomerados subnormais, 2010

\begin{tabular}{l|c|c|c|c|c|c|c}
\hline \multirow{2}{*}{ RMSP } & \multicolumn{7}{c}{ Domicilios em aglomerados sub normais } \\
\cline { 2 - 8 } & Rua & $\begin{array}{c}\text { Beco/ } \\
\text { Travessa }\end{array}$ & Escadaria & Rampa & $\begin{array}{c}\text { Passarela/ } \\
\text { Pinguela }\end{array}$ & $\begin{array}{c}\text { Caminho/ } \\
\text { trilha }\end{array}$ & $\begin{array}{c}\text { Não existe via } \\
\text { de circulação } \\
\text { interna }\end{array}$ \\
\hline RMSP & 33,80 & 58,50 & 3,30 & 0,13 & 0,24 & 1,80 & 2,23 \\
MSP & 26,71 & 64,53 & 3,27 & 0,11 & 0,34 & 1,37 & 3,67 \\
outros municípios & 44,29 & 49,58 & 3,34 & 0,17 & 0,09 & 2,44 & 0,09 \\
\hline
\end{tabular}

Fonte: Censo de 2010. Leitura territorial.

Tabela 20 - RMSP: tipo de acessibilidade ao domicílio, 2010

\begin{tabular}{l|c|c|c|c|c}
\hline \multirow{2}{*}{ RMSP } & \multicolumn{5}{|c}{ Domicílios em aglomerados subnormais } \\
\cline { 2 - 6 } & Caminhão & Carro & Motocicleta & A pé / bicicleta & $\begin{array}{c}\text { Não existem } \\
\text { vias internas }\end{array}$ \\
\hline RMSP & 11,65 & 22,15 & 9,13 & 54,84 & 2,23 \\
MSP & 8,16 & 18,56 & 8,50 & 61,11 & 3,67 \\
outros municípios & 16,82 & 27,45 & 10,06 & 45,58 & 0,09 \\
\hline
\end{tabular}

Fonte: Censo de 2010. Leitura territorial. 
A falta de espaçamento entre unidades domiciliares é evidenciada pela Tabela 17: em 85\% dos domicílios, não há nenhum espaçamento entre eles. Essa proporção praticamente se mantém tanto no município da capital como nos outros municípios da metrópole. Em menos de $1 \%$ há espaçamento grande, situação equivalente à média brasileira. 0 tecido dos aglomerados subnormais é denso, sem espaços vazios, com pouca área livre e pouca superfície para expansão das unidades, que acabam por ter que se verticalizar.

A maior parte dos domicílios favelados localizam-se em margens de rios, córregos e lagos, tanto no município de São Paulo (24,69\%) como nos outros municípios metropolitanos $(25,24 \%)$. São um total de 148.808 unidades de moradia em lugar removível, ao menos em princípio. Outros 212 mil estão em encostas, sujeitos a deslizamentos. Quase 2.000 situam-se em áreas contaminadas, devendo, com certeza, serem realocados, sobretudo na capital. Vale a pena lembrar que na metrópole paulista localizam-se $18 \%$ dos domicílios favelados em áreas contaminadas no Brasil. Em faixas de domínio diversas, temos quase 23 mil casas faveladas, a maior parte sob fios de alta tensão, menos na capital que na periferia metropolitana. Percebe-se também que não há muita variação no padrão de localização na capital e na periferia.

0 arruamento nos aglomerados metropolitanos é deficiente: apenas 33,80\% dos domicílios são servidos por ruas. Em quase $60 \%$, 0 acesso só pode se dar por becos, em 3,5\% por escadas ou rampas. A situação na capital é mais precária: $27 \%$ dos domicílios dão para ruas e $65,5 \%$ para becos ou travessas.

0 arruamento deficiente leva a uma não acessibilidade: na metrópole, 55\% dos domicílios favelados só são acessíveis a pé, situação ainda mais drástica na capital, onde isso acontece em $61 \%$ das unidades domiciliares. Apenas 34\% das casas nos aglomerados são acessíveis por caminhão e/ou carro, proporção bem maior nos municípios da periferia, onde isso se dá em $44 \%$ das unidades. Em projetos de urbanização, esse é um fator importante a ser levado em conta.

\section{0 município de São Paulo}

0 crescimento da população favelada no município de São Paulo na década de 1980 foi de $7,07 \%$ anuais, quase o dobro da taxa de crescimento populacional da população municipal no mesmo período (3,66\% anuais). Entre 1991 e 2000, a população favelada continuou a crescer mais que a população como um todo: $2,50 \%$ ao ano, enquanto a municipal aumentou a uma taxa de apenas $0,92 \%$ anuais. $E$, entre 2000 e 2010, as taxas faveladas se mantiveram maiores que as municipais, atingindo valores superiores à da década de 1990: 3,22\% ao ano, para uma população municipal com crescimento de $0,76 \%$ anuais, mais do que quatro vezes o crescimento municipal.

Até 0 ano 2000, o crescimento da população paulistana era nitidamente periférico: a Tabela 22 mostra as taxas de crescimento da população por anéis, ${ }^{2}$ onde se percebe que entre 1991 e 2000 as taxas dos três anéis centrais como negativas, enquanto a do anel periférico se responsabilizava por praticamente todo 0 crescimento municipal. Esse panorama muda na primeira década do século XXI, com os anéis central e interior com taxas positivas e mais altas que a dos anéis exterior e periférico. 
Tabela 21 - Município de São Paulo.

População total e favelada por anel, 1991 a 2010

\begin{tabular}{l|r|r|r|r|r|r|r|r}
\hline \multirow{2}{*}{ Anel } & \multicolumn{5}{|c|}{ População favelada } & \multicolumn{1}{c}{ População total } \\
\cline { 2 - 9 } & \multicolumn{1}{|c|}{1991} & \multicolumn{1}{c|}{1996} & \multicolumn{1}{c|}{2000} & \multicolumn{1}{c}{2010} & 1991 & 1996 & \multicolumn{1}{c}{2000} & 2010 \\
\hline central & 211 & 0 & 0 & 0 & 384.048 & 334.173 & 318.599 & 360.266 \\
interior & 6.156 & 2.920 & 4.557 & 621 & 686.610 & 609.305 & 583.956 & 648.269 \\
intermediário & 74.053 & 6.329 & 94.610 & 80.247 & 1.413 .723 & 1.319 .467 & 1.316 .367 & 1.426 .682 \\
exterior & 230.416 & 27.361 & 220.365 & 343.520 & 3.265 .900 & 3.194 .496 & 3.304 .779 & 3.414 .917 \\
periférico & 398.223 & 463.822 & 611.096 & 850.422 & 3.860 .378 & 4.378 .382 & 4.911 .845 & 5.403 .336 \\
\hline MSP & 711.050 & 749.318 & 932.628 & 1.280 .400 & 9.610 .659 & 9.853 .823 & 10.435 .546 & 11.253 .470 \\
\hline
\end{tabular}

Fonte: Censos de 1991 a 2010; Contagem de População de 1996.

Tabela 22 - Município de São Paulo

Proporção de favelados na população total, 1991 a 2010, por anéis

\begin{tabular}{l|c|c|c|c}
\hline \multirow{2}{*}{ Anel } & \multicolumn{4}{|c}{ População favelada } \\
\cline { 2 - 5 } & 1991 & 1996 & 2000 & 2010 \\
\hline central & 0,05 & 0,05 & 0,00 & 0,00 \\
interior & 0,90 & 0,90 & 0,78 & 5,10 \\
intermediário & 5,24 & 5,24 & 7,19 & 10,06 \\
exterior & 7,06 & 7,06 & 6,67 & 15,74 \\
periférico & 10,32 & 10,32 & 12,44 & 11,38 \\
\hline MSP & 7,40 & 7,40 & 8,94 & \\
\hline
\end{tabular}

Fonte: Censo de 2010. Leitura territorial.

Tabela 23 -- Município de São Paulo. Taxas geométricas anuais de crescimento populacionais, população total e favelada, por anéis, em porcentagem

\begin{tabular}{l|c|c|c|c}
\hline \multirow{2}{*}{ Anel } & \multicolumn{2}{|c|}{ População total } & \multicolumn{2}{c}{ População favelada } \\
\cline { 2 - 5 } & $1991-2000$ & $2000-2010$ & $1991-2000$ & $2000-2010$ \\
\hline central & $-2,05$ & 1,24 & $-100,00$ & 0,00 \\
interior & $-1,78$ & 1,05 & $-2,70$ & $-18,07$ \\
intermediário & $-0,79$ & 0,81 & 2,25 & $-1,63$ \\
exterior & 0,13 & 0,33 & $-0,40$ & 4,54 \\
periférico & 2,71 & 0,96 & 3,97 & 3,36 \\
\hline MSP & 0,92 & 0,76 & 2,50 & 3,22 \\
\hline
\end{tabular}

Fonte: Censo de 2010. Leitura territorial. 
Tabela 24 - MSP: Densidade demográfica e de domicílios, por anéis, 2010

\begin{tabular}{l|c|c|c|c|c|c|c}
\hline \multirow{2}{*}{ Anel } & \multicolumn{7}{|c}{ Setores censitários em aglomerados subnormais } \\
\cline { 2 - 8 } & Total & $\begin{array}{c}\text { Número de } \\
\text { domicílios } \\
\text { particulares } \\
\text { ocupados }\end{array}$ & $\begin{array}{c}\text { População } \\
\text { residente em } \\
\text { domicilios } \\
\text { particulares }\end{array}$ & $\begin{array}{c}\text { Área } \\
\text { (ha) }\end{array}$ & $\begin{array}{c}\text { Densidade } \\
\text { demográfica } \\
\text { (hab/ha) }\end{array}$ & $\begin{array}{c}\text { Densidade } \\
\text { de domicilios } \\
\text { particulares } \\
\text { ocupados } \\
\text { (dom/ha) }\end{array}$ & $\begin{array}{c}\text { Pessoa/ } \\
\text { domicilio }\end{array}$ \\
\hline central & - & - & - & - & - & - & - \\
interior & 7 & 1.725 & 6.211 & 7 & 913,18 & 253,62 & 3,60 \\
intermediário & 99 & 22.903 & 80.247 & 158,24 & 507,12 & 144,73 & 3,50 \\
exterior & 552 & 94.496 & 343.520 & 789,77 & 434,96 & 119,65 & 3,64 \\
periférico & 1.340 & 236.632 & 850.422 & $3.349,82$ & 253,87 & 70,64 & 3,59 \\
\hline MSP & 1.998 & 355.756 & 1.280 .400 & $4.304,63$ & 297,45 & 82,65 & 3,60 \\
\hline
\end{tabular}

Fonte: Censo Demográfico de 2010. Leitura Territorial.

Tabela 25 - MSP: Topografia dos setores censitários nos aglomerados subnormais, por anéis, 2010

\begin{tabular}{l|r|r|r|r|r|r}
\hline \multirow{2}{*}{ Anéis } & \multicolumn{5}{|c}{ Domicílios em setores censitários de aglomerados subnormais } \\
\cline { 2 - 6 } & \multicolumn{2}{|c|}{ Plano } & \multicolumn{2}{c}{ Aclive/declive moderado } & \multicolumn{2}{c}{ Aclive/declive acentuado } \\
\hline anel central & 0 & - & 0 & - & 0 & - \\
anel interior & 1.725 & $100 \%$ & 0 & $0 \%$ & 0 & $0 \%$ \\
anel intermediário & 20.656 & $90 \%$ & 2.020 & $9 \%$ & 227 & $1 \%$ \\
anel exterior & 40.335 & $43 \%$ & 29.874 & $32 \%$ & 24.287 & $26 \%$ \\
anel periférico & 72.377 & $31 \%$ & 98.385 & $42 \%$ & 65.870 & $28 \%$ \\
\hline MSP & 135.093 & $38 \%$ & 130.279 & $37 \%$ & 90.384 & $25 \%$ \\
\hline
\end{tabular}

Fonte: Censo Demográfico de 2010. Leitura territorial.

Para as favelas, o crescimento na década de 1990 era grande no anel periférico, com quase $4 \%$ anuais. 0 aumento da população favelada no anel intermediário também não era desprezível: 2,25\% anuais. Na década seguinte, de 2000 a 2010, a situação muda: embora os dois anéis mais periféricos cresçam bastante, é no anel exterior que a taxa é maior. De qualquer forma, o município se distingue por apresentar uma favelização predominantemente periférica, com proporção de favelados significativas nos anéis exterior e periférico. A proporção de população favelada nos três anéis mais centrais diminuiu na última década (Tabela 23).

A área total ocupada pelos assentamentos subnormais em 2010 é de 4.404,63 hectares, ou seja, menos de $3 \%$ da superfície total municipal. Essa área, entretanto, é ocupada por $11,38 \%$ do volume populacional. Isso vai resultar em densidades altas, como atestam os dados da Tabela 25, na qual 
se percebe que as densidades das áreas faveladas nos anéis interior (913 hab/ha) e intermediário (507 hab/ha) são altíssimas. Mesmo no anel exterior (434 hab/ha), a densidade demográfica nas favelas é elevada. Apenas no anel periférico ela é um pouco menor, de $253 \mathrm{hab} / \mathrm{ha}$.

As altas densidades se refletem na existência de espaçamento entre unidades domiciliares e no número de pavimentos das unidades. Para o município como um todo, em $84,26 \%$ dos domicílios não há espaçamento, proporção semelhante à da Região Metropolitana de São Paulo, onde em 85,21\% das unidades não havia espaçamento. No anel intermediário é onde existe o maior adensamento, com quase $97 \%$ das unidades de moradia não apresentando nenhum espaço entre elas.
É também no anel intermediário onde as casas com apenas um pavimento se apresentam com menor proporção, apenas 9,20\% das unidades, enquanto quase $90 \%$ têm dois pavimentos.

No anel exterior, tem-se a menor porcentagem de domicílios sem espaçamento, mas uma proporção de unidades com três e mais pavimentos elevada: 6,52\%. Talvez a existência de pouco menos de $20 \%$ das casas com algum espaçamento e a presença de maior verticalização está se refletindo na alta taxa de crescimento dos domicílios favelados nesse anel entre 2000 e 2010, ainda mais alta que no anel periférico. A topografia do anel exterior é um pouco mais adequada que a do anel periférico: no exterior, $26 \%$ dos domicílios situam-se em terrenos com declive acentuado, enquanto no periférico essa proporção sobe para $28 \%$.

Tabela 26 - MSP: Existência de espaçamento entre domicílios em aglomerados subnormais, por anéis, 2010

\begin{tabular}{l|c|c|c|c|c|c}
\hline \multirow{2}{*}{ Distritos } & \multicolumn{5}{|c}{ Domicílios em setores censitários de aglomerados subnormais } \\
\cline { 2 - 6 } & \multicolumn{2}{|c|}{ Sem espaçamento } & \multicolumn{2}{c}{ Espaçamento médio } & \multicolumn{2}{c}{ Espaçamento grande } \\
\hline anel central & - & - & - & - & - & 0 \\
anel interior & 1.414 & $82,0 \%$ & 311 & $18,0 \%$ & 0 & 0 \\
anel intermediário & 22.194 & $96,9 \%$ & 602 & $2,6 \%$ & 107 & $0,5 \%$ \\
anel exterior & 77.229 & $81,7 \%$ & 17.179 & $18,2 \%$ & 88 & $0,1 \%$ \\
anel periférico & 198.907 & $84,1 \%$ & 37.260 & $15,7 \%$ & 465 & $0,2 \%$ \\
\hline MSP & 299.744 & $84,3 \%$ & 55.352 & $15,6 \%$ & 660 & $0,2 \%$ \\
\hline
\end{tabular}

Fonte: Censo Demográfico de 2010. Leitura territorial. 
Tabela 27 - MSP: número de pavimentos dos domicílios em aglomerados subnormais, 2010, por anéis

\begin{tabular}{l|c|c|c|c|c|c}
\hline \multirow{2}{*}{ Anéis } & \multicolumn{5}{|c}{ Domicílios em setores censitários de aglomerados subnormais } \\
\cline { 2 - 6 } & \multicolumn{2}{|c|}{ Um pavimento } & \multicolumn{2}{c}{ Dois pavimentos } & \multicolumn{2}{c}{ Três pavimentos ou mais } \\
\hline anel central & - & - & - & - & - & - \\
anel interior & 576 & $33 \%$ & 1.149 & $67 \%$ & 0 & $0 \%$ \\
anel intermediário & 2.108 & $9 \%$ & 20.572 & $90 \%$ & 223 & $1 \%$ \\
anel exterior & 26.595 & $28 \%$ & 61.740 & $65 \%$ & 6.161 & $7 \%$ \\
anel periférico & 79.144 & $33 \%$ & 148.794 & $63 \%$ & 8.694 & $4 \%$ \\
\hline MSP & 108.423 & $30 \%$ & 232.255 & $65 \%$ & 15.078 & $4 \%$ \\
\hline
\end{tabular}

Fonte: Censo Demográfico de 2010. Leitura territorial.

\section{Considerações finais}

Uma primeira leitura dos dados censitários mostra o número de assentamentos subnormais - proxy das favelas - com forte aumento no Brasil, praticamente dobrando em 19 anos. Se a taxa de incremento anual dos domicílios totais entre 1991 e 2000 era de 0,89\% ao ano, a mesma taxa para os domicílios favelados foi de $4,18 \%$ anuais, ou seja, 4,8 vezes maior. No período seguinte, entre 2000 e 2010, essa razão alcançou mais de 12 vezes $(0,57 \%$ em contraposição a 6,93\% ao ano). Em 2010, 5,61\% da população brasileira, ou 3,2 milhões de pessoas, vivia em favelas. Apesar da diminuição da pobreza e da fome durante a primeira década do século XXI, as condições de moradia são ainda bastante ruins. 0 preço elevado da terra e da moradia faz com que a alternativa da ocupação seja uma das poucas possíveis para grande parte da população brasileira.
Embora em todas as regiões brasileiras a taxa de crescimento favelada tenha aumentado entre as duas últimas décadas, é na região Nordeste onde esse aumento aparece de forma mais nítida, com $11,70 \%$ de taxa de crescimento dos domicílios favelados, taxa quase nove vezes maior que na década 1991 a 2000. Acredita-se que grande parte desse aumento se deva à melhoria de coleta de dados sobre aglomerados subnormais no último Censo Demográfico (2010). Mesmo no Sudeste e no Sul as taxas foram altas, de $4,46 \%$ e $4,41 \%$ ao ano, respectivamente.

Com relação ao acesso à infraestrutura básica, morar em favela no Brasil já não é o mesmo que no século passado: $88 \%$ dos domicílios favelados são servidos por rede pública de água, 56\% por rede de esgoto, 76\% têm algum tipo de coleta de lixo e $72 \%$ usufruem de energia elétrica com medidor domiciliar instalado. A situação infraestrutural é pior no 
Norte e no Nordeste. Por outro lado, o grande incremento de domicílios favelados observado no últimos anos talvez esteja recriando favelas precárias de madeira. Dados preliminares indicam o aumento desse fenômeno na capital paulista: novos assentamentos ressurgem, primeiro com barracas de lona, depois, de madeira e só posteriormente são substituídos por casas de alvenaria.

A análise da leitura territorial, realizada pela primeira vez no Censo de 2010, mostra que quase $20 \%$ dos assentamentos favelados no Brasil situam-se em encostas, e no Nordeste e no Sudeste, a proporção atinge $1 / 4$ dos domicílios, 12\% alocam-se em margens de cursos d'água, e na Região Sudeste essa porcentagem é de $14 \%$. Assim, para se pensar numa estratégia intervenção em áreas de favela, é preciso levar em conta que $32 \%$ dos domicílios favelados situam-se em locais com topografia complicada. 0 levantamento aponta que 89 mil moradias faveladas estão localizadas em sobre antigos aterros sanitários ou lindeiras a vias expressas, rodoviárias ou ferroviárias totalizam. 0 dado é relevante, pois, nesses casos, a única solução possível seria a de remoção.

Para que se efetue uma remoção dentro dos princípios que têm norteado a política de intervenção em favelas, seria necessário realocar as moradias na mesma favela ou em local próximo. Os dados censitários indicam essa solução como problemática, já que em 72,6\% dos casos não há espaçamento entre os domicílios. A solução que tem sido encontrada é o adensamento e a verticalização: $30 \%$ dos domicílios favelados no Brasil já contam com três pavimentos. A densidade demográfica nas favelas brasileiras ainda não é alta, de 67,5 hab/ha, mas no Sudeste já chega a 99 hab/ha e em alguns segmentos espaciais do município de São Paulo alcança quase 1.000 hab/ha. Densidades altas nesse tipo de tecido urbano indicam problemas de insolação, ventilação e circulação, ou seja, indicam unidades residenciais com condições precárias de salubridade e um tecido urbano denso pouco adequado à implantação de redes de infraestrutura urbana, como rede água ou esgotamento sanitário.

Na Região Metropolitana de São Paulo, o incremento anual da população favelada é também superior ao da população total. Entretanto, na década de 2000, percebe-se uma inversão no crescimento das favelas: elas crescem mais no município da capital que nos outros municípios da metrópole, mesmo em uma década onde podem ser contabilizadas várias remoções de favela (como, por exemplo, no perímetro da Operação Urbana Água Espraiada - ver Ferreira, 2014). A densidade demográfica das favelas na metrópole paulista é quatro vezes maior que a densidade média no país, ou seja, atinge 245 hab/ha, num tecido urbano também sem espaçamento e com $62 \%$ dos domicílios com mais de um pavimento.

Tanto a população municipal como a favelada vinham crescendo mais intensamente na periferia da cidade. Entre 2000 e 2010, a população total nos anéis centrais volta a crescer com taxas significativas, embora essas taxas resultem em números absolutos irrisórios: um total de 216.296 habitantes, $26 \%$ do incremento populacional na década. Já a população favelada perdeu números absolutos nos anéis centrais e ganhou nos anéis exterior (123 mil pessoas) e periférico (239 mil favelados). Nota-se, por outro lado, que a taxa de crescimento dos favelados no chamado anel exterior ultrapassa a taxa no anel periférico. As densidades 
demográficas municipais são altas: no anel interior chega a 913 habitantes por hectare. Mesmo no anel periférico, onde ela é menor, alcança 254 hab/ha. Cerca de 90 mil unidades domiciliares situam-se em encostas com declive acentuado, sobretudo nos anéis exterior e periférico. $E$ a verticalização das casas nas favelas do município é grande: $70 \%$ das moradias tem mais de um pavimento. Alguns distritos apresentam grande proporção de favelados. Entre os 96 distritos que compõem o município, há 10 com mais de $20 \%$ da população em favelas. Os dados ilustram o fato de que, entre as 355.756 unidades domiciliares em favela no município de São Paulo, em 2010, 24,70\% alocam-se às margens de cursos de água, quase $2 \%$ são palafitas e 2,5\% estão em unidades de conservação. Isso soma cerca de 102 mil domicílios, estimando-se em mais de 377 mil pessoas sujeitas e constantes riscos de alagamento ou solapamento. A favela ocupa o espaço de forma específica: é precariamente arruado e mais denso que o espaço formal, dois complicadores para serviços urbanos importantes, como o acesso de ambulância, polícia, bombeiros e coleta de lixo. Aliás, a presença de montes de lixo e entulho, atraindo artrópodes, mosquitos e ratos, é uma constante. Em relação à morfologia, a casa favelada paulistana no ano de 2010 era predominantemente de alvenaria $(96,31 \%)$, com uma média de 4,10 cômodos por domicílio e 2,24 pessoas por dormitório. Entre as unidades construídas em alvenaria, $26 \%$ estão sem revestimento. A aparência de um eterno canteiro de obras domina a favela. A precariedade do esgotamento sanitário persiste: pelo Censo de $2000,51 \%$ das casas faveladas paulistanas estavam ligadas à rede pública de esgotos, proporção que aumenta para 67,4\% em 2010, mostrando o resultado da política de urbanização de favelas, tanto municipal como federal. Mas 30\% das unidades não apresenta ainda destino de dejetos adequado. Quase a totalidade das casas faveladas do município usufruíam da rede pública de água, assim como de energia elétrica, e em $67,15 \%$ dos domicílios o medidor era individual. Assim, o espaço favelado tem certa especificidade urbanística, mas suas unidades de moradia aproximam-se das unidades pobres de qualquer loteamento.

Mesmo não sendo objeto deste artigo, um rápido passar de olhos em algumas informações sobre os favelados na capital reitera dados importantes: os favelados paulistanos são mais jovens que a população do município como um todo: apenas 1,48\% têm 65 anos e mais, contra 4,57\% para o total, em 2010. E $22 \%$ do total dos paulistanos têm até 30 anos, enquanto entre os favelados essa proporção é de $28 \%$. Os favelados são majoritariamente pretos ou pardos (61\%), enquanto no município como um todo, essa porcentagem era $37 \%$. E, reiterando que o favelado paulistano não é migrante recente, $75 \%$ dos não naturais de São Paulo moradores nas favelas estão no município há 10 anos e mais. 0 percurso dos favelados distancia-se do imaginário popular, que o tinha como sendo direto da zona rural nordestina para a favela paulistana. Não raro, o favelado experimentou situação habitacional distinta no município, geralmente casa alugada. A impossibilidade do pagamento de aluguel ou de permanência em casa de parente condicionaram a ida para a favela. 0 favelado tende a ser negro ou pardo, mas não é migrante recente nem teve na favela sua primeira residência (ver Meirelles, 2014, e Valladares, 2005). 0 favelado é, antes de 
tudo, um trabalhador pobre: em 2010 o total dos ocupados com mais de 10 anos somava $546.525,42,25 \%$ do total populacional. Entre esses ocupados, mais de $85 \%$ eram empregados, a maioria $(65 \%)$ com carteira de trabaIho. A moradia favelada foi invadida por bens industrializados. Além dos básicos: fogão, rádio e geladeira, a presença maciça da televisão plana e em cores é praticamente universal, assim como a do celular. Em 2010, mais de $26 \%$ dos domicílios favelados no município tinham microcomputador com acesso à internet e $23,5 \%$ possuíam automóvel, porcentagem superior à de 2000 , de $17,9 \%$. As favelas não são um mundo social à parte. A proximidade com distintos segmentos urbanos faz com que espaços favelados apresentem diversos perfis socioeconômicos.
A análise dos dados censitários, com especial destaque à "Leitura Territorial", mostram que a intervenção pública em áreas de favela ainda é uma necessidade premente, seja no que diz respeito à infraestrutura urbana mas também em relação à melhoria das unidades habitacionais. Por outro, com o intenso crescimento das favelas durante a primeira década do século XXI por todo o Brasil, seja em números absolutos ou em densidade, faz com que o desafio da intervenção em áreas faveladas esteja cada vez mais complexo. Em algumas áreas a intervenção sem remoção não é uma possibilidade. Porém, essa não pode ser a justificativa para processos de remoção indiscriminada, como temos observado em várias cidades brasileiras (ver Viana, 2015; Nobre e Bassani, 2015).

\section{Suzana Pasternak}

Universidade de São Paulo, Faculdade de Arquitetura e Urbanismo, Departamento de História. São Paulo/SP, Brasil suzanapasternak@gmail.com

\section{Camila D'Ottaviano}

Universidade de São Paulo, Faculdade de Arquitetura e Urbanismo, Departamento de Tecnologia. São Paulo/SP, Brasil

camila.dottaviano@gmail.com

\section{Notas}

(*) Versão preliminar deste artigo foi apresentada no XIX Encontro Nacional de Estudos Populacionais, realizado em São Pedro, de 24 a 28 de novembro de 2014.

(1) Para efeito deste artigo, aglomerado subnormal é usado como proxy de favela.

(2) Divisão por anéis a partir de metodologia desenvolvida por Taschner (1990). 


\section{Referências}

D'OTTAVIANO, C. e PASTERNAK, S. (2015). Políticas recentes de melhorias urbanas: municípios pequenos e médios e favelas. Revista Brasileira de Estudos Urbanos e Regionais, v. 17, pp. 75-88.

FERREIRA, P. E. (2014). Urbanização de favelas vs desfavelamento: notas sobre uma operação paulistana. 3 CONGRESSO INTERNACIONAL DE HABITAÇÃO NO ESPAÇO LUSÓFONO. Anais. São Paulo, FAUUSP.

FOLHA DE S.PAULO (2015a). Cotidiano, B4, 24 de julho

(2015b). Cotidiano, B1 e B3, 25 de agosto.

GUIMARÃES, B. M. (2000). "As vilas favelas em Belo Horizonte: o desafio dos números". In: QUEIROZ RIBEIRO, L. C. (org.). O futuro das metrópoles: desigualdade e governabilidade. Rio de Janeiro, Revan/Fase, pp. 351-374.

IBGE (1953). As favelas do Distrito federal e o Censo demográfico de 1950. Documentos censitários, Serie C, n. 9. Rio de Janeiro, IBGE.

(1980). Censo Demográfico 1980. Rio de Janeiro, IBGE.

(1991). Censo Demográfico 1991. Rio de Janeiro, IBGE.

(2000). Censo Demográfico 2000. Rio de Janeiro, IBGE.

(2010). Censo Demográfico 2010. Rio de Janeiro, IBGE.

(2011). Censo Demográfico 2010. Aglomerados Subnormais. Primeiros Resultados. Rio de Janeiro, IBGE.

MEIRELLES, R. (2014). Um país chamado favelas: a maior pesquisa já feita sobre a favela brasileira. São Paulo, Gente.

NOBRE, E. A. C. e BASSANI, J. (orgs.) (2015). Intervenções urbanas em áreas em transformação de cidades da América Latina. São Paulo, FAUUSP.

PASTERNAK, S. e D'OTTAVIANO, C. (2014). População favelada no Brasil e no município de São Paulo: as mudanças apontadas pelo Censo de 2010. In: XIX ENCONTRO NACIONAL DE ESTUDOS POPULACIONAIS. Anais. Belo Horizonte, Abep, v. 1, pp. 1-21.

VALLADARES, L. do P. (2005). Do mito de origem à favela. Rio de Janeiro, Editora da Fundação Getúlio Vargas.

VIANA, L. A. (2015). Da conquista à resistência: Copa do Mundo, moradia, remoções e movimentos sociais em Fortaleza-CE. Dissertação de Mestrado. São Paulo, Universidade de São Paulo.

TASCHNER, S. P. (1990). Habitação e demografia intra-urbana em São Paulo. Revista Brasileira de Estudos de População, v. 7, n. 1, pp. 3-34. 
